\title{
FakTor-Faktor YANg Mempengaruhi Tingkat Partisipasi MASYARAKaT Dalam PNPM UNIT PARIWISATa Di Kota SURAKarTa (STUdi KaSUS Kelurahan SONdakan, LaWEyan Dan MoJosongo)
}

\author{
Ratna Devi Septiandari, Kuswanto Nurhadi, Isti Andini \\ Program Studi Perencanaan Wilayah dan Kota, \\ Jurusan Arsitektur, Fakultas Teknik \\ Universitas Sebelas Maret, Surakarta \\ email: ratna.ajah@gmail.com
}

\begin{abstract}
National Program for Community Empowerment (NPCE) Tourism Unit is a new program for poverty alleviation in the region Surakarta. Issues that arise in the village Sondakan, Laweyan and Village Mojosongo was once a thriving get a lot of government programs to poverty due to the potential tourist. Interaction between local communities and the tourists and immigrants affect the level of community participation. This study used a descriptive analysis of quantitative analysis tool is used is a Likert Scale to determine the level of community participation and analysis tools SPSS 17 is used to determine the factors that affect participation. The results showed that the force participation is given at all stages of PNPM Tourism Unit, mind and material donations given to the planning and implementation as well as participation in the form of money given in the stage of implementation and utilization. The level of community participation is quite high. Internal factors that affect the shape and the level of community participation is a factor the type of work, level of income, level of education and public knowledge factor. While external factors that affect the shape and the level of community participation is the city government, village government, LKM and facilitator. For that to the Surakarta City Government is expected to continue to provide support to the development of city infrastructure to ensure the maintenance of continuous functions of tourist infrastructure facilities and infrastructure that has been built. The role of government as a facilitator has become imperative in implementing a program, so that the government needs to increase capacity in the field of technical facilitators.
\end{abstract}

Keywords: Community Empowerment, Participation, PNPM Tourism Unit in Surakarta

\section{PENDAHULUAN}

Pembangunan partisipatif merupakan pendekatan pembangunan yang sesuai dengan hakikat otonomi daerah yang meletakkan landasan pembangunan yang tumbuh berkembang dari masyarakat, diselenggarakan secara sadar dan mandiri oleh masyarakat dan hasilnya dinikmati oleh seluruh masyarakat (Sumaryadi, 2005: 87). Masyarakat yang mandiri tidak dapat diwujudkan secara cepat/instant, melainkan melalui serangkaian kegiatan pemberdayaan masyarakat yang direncanakan, dilaksanakan dan dimanfaatkan oleh masyarakat sendiri. Melalui kegiatan yang dilakukan dari, oleh dan untuk masyarakat, diharapkan upaya penanggulangan kemiskinan dapat berjalan dengan efektif. Partisipasi mayarakat dalam pembangunan sangatlah penting karena berpengaruh terhadap masyarakat itu sendiri. Pada tahun 2013, Kementerian Pariwisata dan Ekonomi Kreatif melaksanakan PNPM (Program Nasional Pemberdayaan Masyarakat) Mandiri Bidang Pariwisata yang memasuki tahun kelima dalam upaya mendukung pengembangan pariwisata melalui kegiatan pemberdayaan masyarakat di kelurahan wisata, di sekitar daya tarik wisata/ kelurahan berbasis industri kreatif, dan kelurahan pendukung usaha pariwisata. Pelaksanaan program mengacu pada Peraturan Menteri Kebudayaan dan Pariwisata Nomor KM.18/HM.001/MKP/2011 tentang Pedoman Program Nasional Pemberdayaan Masyarakat (PNPM) Mandiri Pariwisata. PNPM Unit Pariwisata ini digulirkan di tiga wilayah di Surakarta yaitu Kelurahan 
Sondakan, Laweyan dan Mojosongo seperti pada peta dalam Lampiran 4. Untuk melengkapi Pedoman tersebut, diperlukan Petunjuk Teknis Operasional (PTO) Pelaksanaan PNPM Mandiri Pariwisata Tahun 2013. Dari pencanangan tersebut muncul tugas baru dalam mengembangkan kelurahan wisata agar lebih menarik para wisatawan. Program ini melibatkan berbagai pihak/aktor yaitu pemerintah lokal, organisasi/kelompok swadaya masyarakat, tokoh masyarakat, dan pemerintah kota, swasta (faktor eksternal). PNPM Unit Pariwisata menempatkan masyarakat sebagai objek pembangunan. Dengan keterlibatan masyarakat secara utuh, artinya menempatkan masyarakat lebih sebagai subjek daripada objek, maka upaya melestarikan daya tarik wisata akan lebih mudah mendapatkan tanggapan positif dari masyarakat luas (Warpani, 2007:165).

Bagi masyarakat kelurahan, berkembangnya konsep kelurahan sebagai objek wisata akan memberi dampak positif terutama dari sisi ekonomi. Paling tidak menambah penghasilan warga. Masyarakat sekitar bisa menciptakan lapangan kerja dan meningkatkan kesejahteraan masyarakat lokal. Sementara itu ketersediaan sumber daya manusia juga menjadi faktor kunci penopang keberhasilan program. Oleh karena itu perlu dikaji faktor yang mempengaruhi partisipasi masyarakat dalam PNPM Unit Pariwisata sehingga diketahui kondisinya seperti apa yang berupa faktor internal dan eksternal, agar bisa mengembangkan kelurahan wisata dengan berbagai potensinya. Tujuan dari penelitian ini adalah untuk mengetahui faktor-faktor yang mempengaruhi tingkat partisipasi masyarakat dalam PNPM Unit Pariwisata di Kelurahan Sondakan, Laweyan dan Mojosongo berdasarkan indikator-indikator yang mempengaruhi tingkat partisipasi dengan menggunakan SPSS 17 serta diperolehnya potensi dan masalah pengembangan kelurahan wisata.

\section{METODE}

\subsection{Ruang Lingkup}

Ruang lingkup wilayah dalam penelitian ini adalah lokasi kelurahan penerima dana BLM (bantuan langsung tunai) PNPM Unit Pariwisata di Kota Surakarta meliputi Kelurahan Sondakan, Laweyan dan Mojosongo dengan menitikberatkan pada penyediaan fasilitas penunjang wisata/ sarana dan prasarana pendukung pariwisata yang berupa keanekaragaman kekayaan alam, budaya dan hasil buatan manusia maupun fasilitas usaha pariwisata dan industri kreatif yang menjadi penggerak kegiataan kepariwisataan dikelurahan wisata.

Dalam penelitian ini, variabel yang digunakan dibatasi pada aspek bentuk partisipasi masyarakat, tingkat partisipasi, faktor internal, faktor eksternal yang mempengaruhi tingkat partisipasi masyarakat dalam PNPM Unit Pariwisata.

\subsection{Metode Analisis}

Penelitian ini menggunakan metode deskriptif kuantitatif menyajikan data dengan menggunakan angka dan dianalisis dengan menggunakan teknik statistik (Arikunto (2006:10-14). Dalam penentuan populasi yang akan diambil dalam penelitian ini digunakan metode simple random sampling, merupakan teknik pengambilan sempel anggota populasi dilakukan secara acak tanpa memperhatikan strata yang ada dalam populasi itu (Sugiyono, 2010:120). Analisis SPSS yang digunakan melalui beberapa langkah, antara lain:

1. Menganalisis partisipasi masyarakat setiap tahapan PNPM unit pariwisata.

2. Menganalisis karakteristik faktor yang mempengaruhi tingkat partisipasi masyarakat dalam program PNPM unit Pariwisata dengan analisis deskriptif kuantitatif metode distribusi frekuensi dan pembobotan.

3. Menganalisis faktor yang mempengaruhi tingkat partisipasi masyarakat melalui PNPM Unit Pariwisata dengan analisis deskriptif kuantitatif di Kelurahan Sondakan, Laweyan dan Mojosongo.

\section{HASIL DAN PEMBAHASAN}

\subsection{Analisis Karakter PNPM Unit Pariwisata}

Analisis ini dibuat dengan dasar bahwa program PNPM UP di Kota Surakarta ini tergolong baru, yang dibutuhkan masyarakat untuk menggali potensi wisata yang ada di kelurahan dan membuka akses informasi dan pemasaran untuk mendukung kegiatan 
wisata. Meskipun demikian, kegiatan PNPM UP ini tidak hanya sebatas membangun program fisik saja, tetapi lebih dimaksudkan untuk menyiapkan tatanan sosial masyarakat yang lebih baik sekaligus memberdayakan masyarakat agar mampu berdaya dan berfikir kreatif untuk mengembangan kelurahan wisata. Pengembangan masyarakat melalui pengembangan kapasitas masyarakat dan kelembagaan dan penyelenggaraan pembangunan kelurahan sesuai dengan kebutuhan masyarakat sangat dibutuhkan untuk penguatan kelurahan wisata melalui PNPM Unit Priwisata. Analisis ini berupa analisis proses partisipasi masyarakat dalam tahap perencanaan dan pelaksanaan dan analisis aktor dan peran aktor dalam PNPM Unit Pariwisata. Aktor internal terdiri dari Lembaga Keswadayaan Masyarakat, kelompok swadaya masyarakat, dan tokoh masyarakat. Sedangkan aktor eksternal terdiri dari pemerintah kota, fasilitator, pemerintah kelurahan dan tim teknis kegiatan. Karena pada dasarnya pengembangan kelurahan wisata ini ditujukan untuk memberdayakan agar lebih mandiri. Aktor yang paling berperan dalakarena mendampingi masyarakat penerima program, melakukan sosialisasi program, orientasi lapangan serta berperan dalam pembuatan kaporan pertanggungjawaban kegiatan PNPM Unit Pariwisata di Kota Surakarta.

\subsection{Analisis Bentuk dan Tingkat Partisipasi masyarakat.}

Bentuk partisipasi yang paling banyak di Kelurahan Sondakan adalah sumbangan dalam bentuk dana. Bentuk partisipasi yang paling banyak di Kelurahan Laweyan yaitu berupa sumbangan pikiran. Bentuk partisipasi yang paling banyak di Kelurahan Mojosongo yaitu, berupa sumbangan pikiran/ keahlian/gagasan. Sumbangan pikiran dan gagasan tersebut diberikan masyarakat adalah berupa usulan/saran dan kritik dalam forum pertemuan yang diadakan. Pada tahap pelaksanaan partisipasi masyarakat berupa sumbangan barang/material, tenaga bahkan konsumsi juga untuk kegiatan PNPM UP sebagai wujud partisipasinya. Sumbangan dalam bentuk tenaga ini berupa tenaga untuk kegiatan pembangunan prasarana wisata. Bentuk partisipasi berupa material terlihat di Kelurahan Mojosongo, yang berupa pasir, batu, kerikil untuk pembuatan shelter dan pavingisasi jalan menuju Pagoda. Analisis bentuk dan tingkat partisipasi ini bertujuan untuk mengetahui tingkat partisipasi masyarakat. Analisis ini dilakukan dengan teknik skoring berdasarkan hasil kuesioner yang diperoleh dari masyarakat penerima program. Pada tahap perencanaan tingkat partisipasi di Kelurahan Sondakan dikatakan tinggi apabila nilai skoring 1309-1744. Untuk Kelurahan Laweyan 169-224, dan Kelurahan Mojosongo dengan nilai 33014400. Berdasarkan analisis skoring dapat diketahui bahwa tingkat partisipasi di Kelurahan Sondakan, Laweyan dan Mojosongo adalah sedang. Pada tahap pelaksanaan tingkat partisipasi di Kelurahan Sondakan dan Mojosongo adalah sedang, Namun tingkat partisipasi di Kelurahan Laweyan tergolong tinggi, hal ini dikarenakan pada tahap pelaksanaan banyak dihadiri oleh pelaku usaha dan wilayah Kelurahan Laweyan merupakan wilayah terkecil di Surakarta.

\subsection{Analisis Faktor Pengaruh Tingkat Partisipasi.}

Faktor internal dalam penelitian ini merupakan karakteristik responden yang terdiri dari usia, jenis kelamin, tingkat pendidikan, tingkat pendapatan dan jumlah tanggungan keluarga. Uji statistik yang dilakukan menggunakan uji Pearson correlation, Chi Square, dan regresi ordinal. Berdasarkan hasil analisis di Kelurahan Sondakan menunjukkan bahwa hubungan antara tingkat usia, tingkat pendapatan, dan jumlah tanggungan keluarga terhadap tingkat partisipasi masyarakat di Kelurahan Sondakan terdapat hubungan yang sangat rendah dan memiliki nilai korelasi 0,025 yang artinya bahwa mempunyai hubungan yang positif, apabila semakin tinggi tingkat usia, maka akan semakin meningkatkan partisipasi masyarakat dalam PNPM UP seperti pada Lampiran 1 bahwa nilai korelasi tingkat usia Kelurahan Laweyan -0,332 dengan 
hubungan sangat negatif, yang berarti bahwa semakin tinggi tingkat usia maka akan semakin menurunkan tingkat partisipasi masyarakat dalam PNPM UP. Nila korelasi tingkat pendapatan 0,170 yang berarti mempunyai hubungan positif, semakin besar tingkat pendapatan maka akan semakin meningkatkan tingkat partispasi masyarakat di Kelurahan Laweyan. Nilai korelasi jumlah tanggungan keluarga yaitu $-0,082$ yang berarti bahwa mempunyai hubungan yang negatif, semakin besar jumlah tanggungan keluarga maka semakin menurunkan tingkat partisipasinya dalam kegiatan PNPM UP seperti pada Lampiran 2. Dari tabel nilai pearson correlation di Kelurahan Mojosongo menunjukkan bahwa nilai korelasi tingkat usia yaitu 0,037 yang berarti bahwa mempunyai hubungan yang positif, semakin tinggi tingkat usia maka semakin tinggi tingkat partisipasinya. Nilai korelasi tingkat pendapatan -0,34 yang berarti bahwa mempunyai hubungan yang negatif, semakin tinggi tingkat pendapatan maka tingkat partisipasi akan menurun. Hal itu serupa dengan pendapat Wicaksono (2010), tingkat pendapatan seseorang tidak mempengaruhi partisipasi seseorang dalam suatu kegiatan. Nilai korelasi jumlah tanggungan keluarga adalah $-0,64$ yang berarti mempunyai hubungan yang negatif, semakin tinggi jumlah tanggungan keluarga, maka tingkat partisipasi akan menurun dengan besarnya keeratan hubungan sebesar 0,6 atau kuat seperti dalam Lampiran 3.

Analisis selanjutnya menggunakan chi Square dengan indikator jenis kelamin, tingkat pendidikan dan jenis pekerjaan adalah untuk mencari hubungan antar dua variabel atau lebih di mana variabelvariabel tersebut bersifat kategori. Apabila pearson chi square $<0,05$ maka memiliki pengaruh terhadap tingkat partisipasi. Nilai signifikansi hubungan antara jenis kelamin dan jenis pekerjaan dengan tingkat partisipasi masyarakat di Kelurahan Sondakan sebesar 0,137 dan 0,321 . Hal ini menunjukkan bahwa tidak terdapat hubungan yang signifikan antara jenis pekerjaan dengan tingkat partisipasi pada selang kepercayaan 95\% ( $>>0,05)$. Hal ini berarti bahwa baik laki-laki maupun perempuan tidak mempengaruhi keaktifan untuk berpartisipasi dalam PNPM UP. Sedangkan tingkat pendidikan dengan nilai signifikasnsi 0,001 hal ini berarti ada pengaruh antara tingkat pendidikan dengan tingkat partisipasi dalam PNPM UP. Nilai signifikansi hubungan antara tingkat pendidikan, jenis pekerjaan dengan tingkat partisipasi masyarakat di Kelurahan Laweyan sebesar 0,032 dan 0,049. Hal ini menunjukkan bahwa terdapat hubungan yang signifikan antara jenis pekerjaan dan tingkat pendidikan dengan tingkat partisipasi pada selang kepercayaan $95 \%$ ( $>>0,05)$. Hal ini berarti bahwa jenis pekerjaan mempengaruhi keaktifan untuk berpartisipasi dalam PNPM UP di Kelurahan Laweyan. Tingkat pendidikan, jenis pekerjaan, jenis kelamin di Kelurahan Mojosongo tidak memberikan pengaruh terhadap tingkat partisipasi masyarakat, pendidikan yang rendah justru menjadi peluang bagi masuknya informasi, karena masyarakat yang pendidikannya rendah akan lebih antusias mencari hal -hal yang baru dan terbiasa dengan hal-hal yang sederhana apabila ada kegiatan yang mereka anggap menguntungkan masyarakat.

\subsection{Analisis faktor Pengaruh Eksternal Partisipasi.}

Faktor ekstenal yang dimaksud dalam penelitian ini yaitu kepemimpinan dan keaktifan pihak luar (pemerintah kota, LKM, fasilitator, kelurahan, dan tim teknis) dalam mengajak masyarakat untuk mengikuti kegiatan PNPM UP. Untuk mengetahui pengaruh faktor eksternal terhadap tingkat partisipasi masyarakat dalam PNPM UP digunakan alat SPSS regresi ordinal, karena datanya berwujud data skala ordinal dengan tingkat signifikansi $<0,05$ yang menunjukkan ada pengaruh faktor eksternal terhadap tingkat partisipasi .

Berdasarkan tabel nilai hasil analisis regresi ordinal dan tabel tingkat signifikansi dan hasil perhitungan dengan menggunakan SPSS dapat di katakan bahwa bahwa kepemimpinan/peran 
seluruh faktor-faktor eksternal meliputi peran fasilitator dan LKM memberi pengaruh terhadap tingkat partisipasi di Kelurahan Sondakan. Namun peran seluruh aktor eksternal di Kelurahan Laweyan tidak memberikan pengaruh terhadap tingkat partisipasi karena nilai signifikansi lebih dari 0,05 . Hal ini juga sesuai dengan kondisi di lapangan karena Kelurahan Laweyan sering digunakan untuk penelitian, maka masyarakat sudah terbiasa dengan adanya penelitian atau pun program-program yang digulirkan oleh pemerintah. Sedangkan faktor fasilitator dan LKM memberikan pengaruh terhadap tingkat partisipasi masyarakat di Kelurahan Mojosongo karena nilai tingkat signifikansi $<0,05$ dengan melihat kenyataan bahwa tingkat partisipasi masyarakat berada pada tingkat sedang artinya tidak terlalu rendah dan tidak terlalu tinggi. Faktor-faktor yang memberikan pengaruh tersebut harus dikaji lebih jauh peran dan kontribusi terhadap tinggi rendahnya tingkat partisipasi masyarakat.

\subsection{Sintesa faktor yang paling berpengaruh. \\ Dalam pembahasan sintesa ini dapat} dijabarkan dan dirangkum bahwa tingkat partisipasi terdiri dari tingkat partisipasi pada tahap perencanaan dan pelaksanaan. Faktor pengaruh internal dan eksternal tidak semua memberikan pengaruh terhadap tingkat partisipasi di Kelurahan Sondakan, Laweyan dan Mojosongo. Sintesa ini menjabarkan faktor-faktor apa yang mempengaruhi tingkat partisipasi masyarakat di Kelurahan Sondakan, Laweyan dan Mojosongo berdasarkan data yang diolah dan analisis SPSS 17 menunjukkan bahwa faktor internal yang meliputi tingkat pendidikan di Kelurahan Sondakan memberikan pengaruh terhadap tingkat partisipasi yaitu terhadap kehadiran dan keaktifan berdiskusi responden dalam pertemuan. Semakin tinggi pendidikan seseorang maka responden akan lebih banyak memberikan sumbangan pikirannya dengan tingkat pengetahuan yang berbeda dalam pemanfaatan kegiatan PNPM Unit
Pariwisata. Faktor peran fasilitator dan tim teknis serta peran LKM memberikan pengaruh terhadap tingkat partisipasi masyarakat karena fasilitator adalah seseorang yang menjadi penggerak suatu program, apabila fasilitator memberikan arahan yang baik terkait program, maka masyarakat akan mengikuti apa yang menjadi arahan fasilitator dalam pelaksanaan kegiatan.

Tingkat pekerjaan dan tingkat pendidikan memberikan pengaruh terhadap tingkat partisipasi masyarakat di Kelurahan Laweyan, hal ini dikarenakan masyarakat Laweyan mayoritas adalah pengusaha batik dengan karakteristik masyarakat yang terdiri dari kelompok juragan (pedagang), wong cilik (orang kebanyakan), wong mutihan (Islam atau alimulama) dan priyayi (bangsawan/pejabat) (Priyatmono, 2004). Puncak struktur sosial dalam masyarakat Laweyan disebut keluarga majikan sedangkan status di bawahnya adalah kelompok tenaga kerja di perusahaan batik. Untuk menjadikan destinasi wisata di Laweyan dibutuhkan partisipasi masyarakat untuk memelihara bangunan bersejarah, seiring dengan meningkatnya intensitas kegiatan komersil seperti perdagangan dan perkantoran, maka kampung batik Laweyan semakin lama terdesak oleh bangunan-bangunan baru yang lebih memiliki nilai ekonomis. Selain peran serta aktif pemerintah dan masyarakat juga diperlukan adanya peran pihak swasta dan Lembaga Swadaya Masyarakat (LSM) dalam upaya pelestarian. Melalui PNPM Unit Pariwisata bisa mensinergikan antara program pengembangan wisata dengan penguatan kapasitas pelaku wisata di Laweyan salah satunya melalui sosialisasi tentang peraturan/kebijakan tentang pelestarian cagar budaya, pemberian pengahargaan kepada pemilik/pengelola cagar budaya baik berupa piagam, plakat atau trofi serta memfasilitasi kegiatan industri batik (usaha kecil menengah/UKM) melalui bantuan modal, promosi serta pemasaran batik agar kegiatan batik sebagai salah satu ciri khas kawasan Kampung Laweyan dapat 
dilestarikan. Mojosongo merupakan wilayah kelurahan terbesar di Kota Surakarta dan juga merupakan daerah relokasi. Usia dan jumlah tanggungan keluarga di Kelurahan Mojosongo memberikan pengaruh terhadap tingkat partisipasi masyarakat. Hal ini juga ditunjukkan dengan data monografi Kelurahan Mojosongo sebanyak 10.986 orang adalah pensiunan sehingga bisa dikatakan usia masyarakat $>55$ tahun dan mempunyai pengaruh terhadap tingkat partisipasi masyarakat. Melalui PNPM Unit Pariwisata ini kelurahan ini dapat tergali potensi wisatanya yaitu dengan adanya kemajemukan masyarakat dengan berbagai aliran budaya dan kesenian. Namun masih ada kendala dan permasalahan dalam pengembangan wisata di Mojosongo yaitu kurangnya publikasi dari Pemerintah Kota untuk mengangkat potensi ke pariwisataan di kelurahan dan adanya wisata Putri Cempo yang terkendala akses jalan karena wisata tersebut berada di TPA (Tempat Pembuangan Akhir) sampah.

\section{KESIMPULAN}

Secara umum proses kegiatan PNPM UP di Kota Surakarta yaitu Kelurahan Sondakan, Laweyan dan Mojosongo sudah berjalan lancar, dengan program yang berbeda-beda sesuai dengan potensi wilayah. Sesuai olahan analisis tingkat partisipasi tergolong sedang. Hal ini berarti tingkat partisipasi tidak rendah dan tidak begitu tinggi.

Faktor usia dan tingkat pendidikan mempengaruhi tingkat partisipasi masyarakat di Kelurahan Sondakan. Faktor internal jenis pekerjaan dan tingkat pendidikan memberikan pengaruh terhadap tingkat partisipasi masyarakat di Kelurahan Laweyan. Faktor tingkat pendapatan memberikan pengaruh pada tahapan pelaksanaan PNPM UP di Kelurahan Mojosongo, karena pada bentuk partisipasi yang diberikan juga dominan berupa material dan dana. Sedangkan tingkat pendidikan, jenis pekerjaan, jenis kelamin di Kelurahan Mojosongo tidak memberikan pengaruh terhadap tingkat partisipasi masyarakat.
Faktor peran fasilitator dan LKM berpengaruh terhadap seluruh tingkat partisipasi di Kelurahan Sondakan dan Mojosongo. Namun peran seluruh faktor eksternal tidak memberikan pengaruh pada Kelurahan Laweyan karena nilai signifikansi >0,05. Hal ini karena masyarakat Laweyan, sudah terbiasa berpartisipasi aktif dalam setiap kegiatan pemberdayaan yang digulirkan oleh pemerintah. Jadi, tanpa pendampingan pun mereka sudah bisa berjalan. Sebaiknya mengingat potensi wilayah yang cukup bagus, bisa meminta sumbangan/donatur kepada CSR yang ada di lingkungan sekitar kelurahan, jadi bisa lebih maksimal dalam pengelolaan potensi wisata di Kelurahan Sondakan, Laweyan dan Mojosongo

\section{REFERENSI}

Arikunto, S. 2006. Prosedur Penelitian Suatu Pendekatan Praktik, Ed Revisi VI, Jakarta : Rhineka Cipta.

Pedoman Umum PNPM Unit Pariwisata Tahun 2011 .

Sugiyono. 2010. Metode Penelitian Kuantitatif Kualitatif dan $R \& D$. Bandung: Alfabeta.

Peraturan Menteri Kebudayaan dan Pariwisata Nomor: KM.18/ HM.001/MKP/2011

Sumaryadi, I Nyoman, 2005, Perencanaan Pembangunan Daerah Otonomi \& Pemberdayaan Masyarakat, Jakarta : Citra Utama.

Warpani Suwardjoko, dan Indira P. 2007. Pariwisata dalam Tata Ruang Wilayah. Bandung : ITB

Wicaksono MA. 2010. Analisis Tingkat Partisipasi Warga dalam Tanggung Jawab Sosial Perusahaan (Studi Kasus PT. Isuzu Astra Indonesia Assy Plant Pondok Ungu). Skripsi. Bogor : IPB. 


\section{Lampiran 1}

Tabel Hubungan Antara Usia, Tingkat

Pendapatan,dan Jumlah Tanggungan Keluarga

dengan Tingkat Partisipasi Kelurahan Sondakan.

\begin{tabular}{|c|c|c|}
\hline $\begin{array}{c}\text { Hubungan antara } \\
\text { usia, tingkat } \\
\text { pendapatan,dan } \\
\text { jumlah tanggungan } \\
\text { keluarga dengan } \\
\text { tingkat partisipasi. }\end{array}$ & Nilai Korelasi & Keterangan \\
\hline Tingkat Usia & 0.025 & $\begin{array}{c}\text { Hubungan } \\
\text { Sangat rendah }\end{array}$ \\
\hline $\begin{array}{c}\text { Tingkat Pendapatan } \\
\text { Hubungan } \\
\text { Sangat rendah }\end{array}$ \\
\hline $\begin{array}{c}\text { Jumlah Tanggungan } \\
\text { keluarga }\end{array}$ & $-0,047$ & $\begin{array}{c}\text { Hubungan } \\
\text { Sangat rendah }\end{array}$ \\
\hline
\end{tabular}

\section{Lampiran 2}

Tabel Hubungan Antara Usia, Tingkat

Pendapatan, dan Jumlah Tanggungan Keluarga

Dengan Tingkat Partisipasi Kelurahan Laweyan.

\begin{tabular}{|c|c|c|}
\hline $\begin{array}{c}\text { Hubungan antara } \\
\text { usia, tingkat } \\
\text { pendapatan,dan } \\
\text { jumlah tanggungan } \\
\text { keluarga dengan } \\
\text { tingkat partisipasi. }\end{array}$ & $\begin{array}{c}\text { Nilai } \\
\text { Korelasi }\end{array}$ & Keterangan \\
\hline Tingkat Usia & $-0,332$ & $\begin{array}{c}\text { Hubungan } \\
\text { Sangat rendah }\end{array}$ \\
\hline $\begin{array}{c}\text { Tingkat } \\
\text { Pendapatan }\end{array}$ & 0,170 & $\begin{array}{c}\text { Hubungan } \\
\text { Sangat rendah }\end{array}$ \\
\hline $\begin{array}{c}\text { Jumlah } \\
\text { Tanggungan } \\
\text { keluarga }\end{array}$ & $-0,082$ & $\begin{array}{c}\text { Hubungan } \\
\text { Sangat rendah }\end{array}$ \\
\hline
\end{tabular}

\section{Lampiran 3}

Tabel Hubungan Antara Usia, Tingkat

Pendapatan,dan Jumlah Tanggungan Keluarga

Dengan Tingkat Partisipasi Kelurahan Mojosongo.

\begin{tabular}{|c|c|c|}
\hline $\begin{array}{c}\text { Hubungan antara } \\
\text { usia, tingkat } \\
\text { pendapatan,dan } \\
\text { jumlah tanggungan } \\
\text { keluarga dengan } \\
\text { tingkat partisipasi. }\end{array}$ & $\begin{array}{c}\text { Nilai } \\
\text { Korelasi }\end{array}$ & Keterangan \\
\hline Tingkat Usia & 0,037 & $\begin{array}{c}\text { Hubungan } \\
\text { Sangat rendah }\end{array}$ \\
\hline $\begin{array}{c}\text { Tingkat Pendapatan } \\
\text { Hubungan } \\
\text { Sangat rendah }\end{array}$ \\
\hline $\begin{array}{c}\text { Jumlah Tanggungan } \\
\text { keluarga }\end{array}$ & $-0,34$ & $\begin{array}{c}\text { Hubungan } \\
\text { Kuat }\end{array}$ \\
\hline
\end{tabular}




\section{Lampiran 4}

Peta Lokasi Kelurahan Penerima Program

PNPM Unit Pariwisata

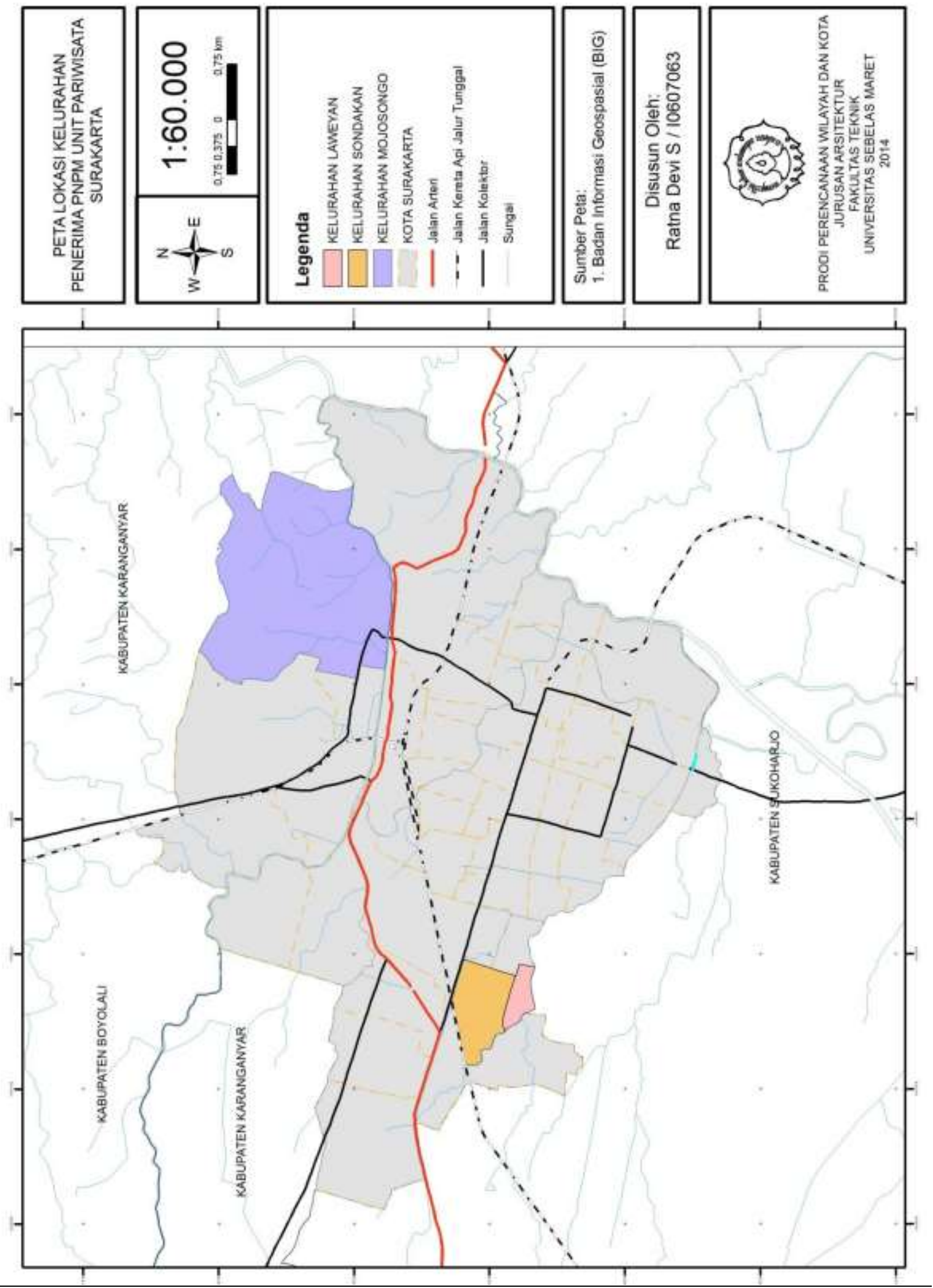

